\section{La pugna de las memorias. Chile, cuarenta años después*}

The struggle of memories. Chile forty years later

JoAn AlcÁZAR-GarRIDo**

\section{Resumen}

Han pasado cuatro décadas desde que el Ejército chileno se sublevó contra el Gobierno de Salvador Allende. Los años pasan, pero las memorias individuales y de grupo de ese período -entendidas como discursos sobre el pasado- continúan siendo beligerantemente contradictorias, como evidencia la controversia todavía existente entre las figuras de Allende y Pinochet. Esa realidad nos preocupa en la medida que los jóvenes que no vivieron los años de plomo se adscriben - de manera poco

Este texto forma parte de una de las líneas de investigación en las que trabajo desde hace años, como resultado de la cual han visto la luz diversas publicaciones. La más reciente, con un título parecido, fue la que apareció en la revista ecuatoriana Universitas. Puede consultarse en http://universitas.ups.edu.ec/ documents/1781427/5884602/Uni_n20_Alcazar.pdf

** Departamento de Historia Contemporánea, Universidad de Valencia: jalcazar@uv.es crítica-, a la memoria dominante en su espacio vital próximo. Construir una memoria para el futuro, incrementando la dosis de conocimiento histórico de los jóvenes chilenos, podría favorecer el reconocimiento de las diferencias políticas internas hasta hacerlas compatibles con una convivencia democrática de calidad.

Palabras clave: Chile, historia, memoria, jóvenes, democracia.

\section{Abstract}

Four decades have passed since the Chilean Army was revolted against the government of Allende. Years pass, but individual and group memoirs - understood as discourses about the past - of this period remain belligerently contradictory, as evidenced by the dispute between the figures of Allende and Pinochet. We are concerned about this reality because young people who didn't live the leaden years are ascribed - uncritically - to the dominant memory in their closest living space. Build a memory for the future, by increasing the dose of historical knowledge of young Chileans, could favor the recognition of internal political differences until making them compatible with a democratic coexistence of quality.

Key words: Chile, history, memory, youth, democracy 


\section{Introducción}

Cuarenta años después del golpe militar que acabó con la vida y con el gobierno de Salvador Allende, Chile continúa padeciendolainexistencia de consensos básicos respecto al relato de su pasado próximo. Esta tesis puede comprobarse fácilmente. Un ejemplo: los dos personajes más importantes de su historia reciente siguen siendo objeto de filias, fobias y comparaciones con frecuencia acríticas. Hablamos de Salvador Allende y de Augusto Pinochet. Se trata de dos figuras de la historia contemporánea de Chile que, como seres humanos, poco tienen que ver el uno con el otro. Ambos personajes vivieron con proximidad física un período breve, intenso y crucial de la historia del país andino. Allende llegó a La Moneda por los cauces constitucionales y creyó hasta el final en la lealtad del general golpista. Pinochet lo hizo a punta de bayoneta y simuló su respeto a una autoridad a la que aborrecía. La victoria del general golpista, que se dijo patriota, significó la muerte del presidente que se quiso revolucionario.

Han pasado los años y en Chile ambos personajes siguen siendo extremadamente controvertidos. Fuera del país, no obstante, la imagen de Pinochet está asociada a lo peor del ser humano. Paralelamente, la imagen de Allende perdura como muy positiva en parte gracias a una cierta mitificación que resalta sus aciertos y virtudes, y oculta sus errores y sus déficits.

Estas páginas obedecen a un interés por colaborar en la construcción de un discurso histórico coherente y veraz para las jóvenes generaciones que no deben ser rehenes de un pasado sobre el que no tienen responsabilidad alguna. Es necesario procurar un mejor conocimiento histórico a la juventud chilena, por ejemplo, sobre estos dos personajes que siguen polarizando los discursos contradictorios - cuando no excluyentes- sobre ese pasado reciente de su país.

\subsection{La confrontación Allende vs. Pinochet como síntoma}

Es en nuestra opinión una evidencia que los dos grandes actores individuales citados han vertebrado la historia reciente de Chile. En unas declaraciones al diario español El País, el ex presidente Patricio Aylwin decía hace menos de un año que Salvador Allende "no fue buen político" (Montes 2012) y le responsabilizó de la triste suerte de Chile a partir de 1970. Al más que caldeado ambiente interno se añadió la celebración, pocos días después, de un homenaje a Augusto Pinochet a cargo de nostálgicos del general. Esto agitó todavía más las aguas políticas chilenas. El festejo terminó con importantes incidentes que ponen de relieve que ambos personajes siguen suscitando aún mucha confrontación entre sus respectivos valedores y contrarios.

Atendamos a la última hiriente controversia de la que hemos tenido conocimiento. Aunque parezca mentira, la extrema derecha todavía insulta a Allende, como se pudo comprobar en septiembre de 2012 en el parlamento de Valparaíso, con motivo del trigésimo noveno aniversario del golpe militar. Sigue siendo una tristísima realidad: una parte de la derecha autóctona parece que no solo no está a favor de la reconciliación de los chilenos, sino que ni siquiera parece aceptar la idea del reencuentro como fase previa. Cuando Michelle Bachelet era ministra de defensa, allá por el 2003, reflexionaba en una entrevista en el diario El Mercurio -con motivo del 30 aniversario del Golpe- a propósito 
de la necesidad de trabajar conjuntamente por el reencuentro de sus compatriotas:

"Sin buscarlo $-y$, probablemente, sin imaginarlo tampoco-, Michelle Bachelet se ha convertido en un símbolo de la reconciliación. Ella, sin embargo, prefiere usar otras palabras y no esa; reencuentro, por ejemplo, le acomoda mejor, la siente más suya". La actual ministra de defensa lo aclara en la entrevista: "Por eso no uso, en general, las palabras perdón o reconciliación. Reconciliación, porque es un asunto muy personal. Para que haya reconciliación a nivel colectivo requiere que haya más verdad y justicia. No se puede borrar el pasado. Primero porque es imposible. Segundo, porque es peligroso no aprender de las lecciones de la historia. Y tercero, porque como médico sé que para que una herida sane tiene que estar limpiecita" (El Mercurio 2003) ${ }^{1}$.

Lo era hace diez años y hoy sigue siendo una tarea en absoluto sencilla, porque se trata de una sociedad fragmentada por un traumatismo tan fuerte como fue la dictadura militar encabezada por el general Pinochet. Todavía treinta y nueve años después del suicidio del doctor Allende en un Palacio de la Moneda sitiado por las tropas golpistas, un diputado de la ultraderecha insultó públicamente la memoria del presidente socialista. La noticia fue, claro, ampliamente recogida en los medios:

\footnotetext{
"Al inicio de la sesión de este martes en la Cámara de Diputados, el diputado René Alinco (Ind) solicitó realizar un minuto de silencio en memoria de las víctimas y del fallecido Presidente Allende, petición que fue acogida por el presidente de la Cámara, Nicolás Monckeberg (RN). Sin embargo, el momento fue interrumpido por el diputado Urrutia, quien cuestionó la decisión. “¿A los cobardes que se suicidaron ese día también le vamos a rendir homenaje? ¿Al cobarde que se suicidó ese día también? No puedo creerlo, presidente", manifestó el parlamentario de la UDI"”.
}

El Mercurio, 05 de septiembre de 2003.

http://www.emol.com/noticias/nacional/2012/09/11/560026/ diputado-udi-que-interrumpio-minuto-de-silencio-en-el-congresocon-insulto-a-allende.html (Consultado en febrero de 2014).
Partidarios y detractores han representado, -y en buena medida siguen representando-, dos polos opuestos como referentes políticos tanto en Chile como más allá de sus fronteras. Salvador Allende se suicidó en la sede de la Presidencia de la República, en el Palacio de La Moneda, mientras era asediado por tierra y aire por tropas al mando de Augusto Pinochet, quien no sólo prohibió a sus subordinados negociar nada con el presidente legítimo, sino que además de exigirle rendición incondicional especuló -en un tono supuestamente jocosocon la posibilidad de ponerlo en un avión rumbo a Cuba y que el aparato se estrellara antes de llegar a su destino.

Desde ese 11 de septiembre de 1973, Augusto Pinochet reinó en Chile sin cortapisas, y lo hizo hasta que el plebiscito de 1988 amputó su mandato de forma inesperada. Pese a ello, durante los años en que continuó como Comandante en Jefe se mantuvo amenazante hasta que, fatalmente para él, viajó a Inglaterra en 1998. Allí ‘murió' (políticamente, se entiende), tras pasar más de quinientos días retenido por la policía británica a la espera de la resolución de sus tribulaciones jurídicas para evitar ser extraditado a España. En 2006 escribimos:

\footnotetext{
"Desde la muerte política, ocurrida en Londres en el otoño de 1998, el general no ha sido sino un cadáver molesto. Hoy, frente al Palacio de La Moneda, una estatua afable de Salvador Allende preside la amplia y hermosa explanada. Jamás habrá sitio en ella para Augusto Pinochet Ugarte. Ya no quedan ni sus huesos, convertidos en cenizas por sus familiares para prevenir una hipotética profanación de la tumba, y los chilenos son ahora más libres para definir su presente y su futuro" (Alcázar, J. 2009, p.121).
}

Los treinta y tres años que mediaron entre la muerte de Salvador Allende y la suya estuvieron marcados para Pinochet por el dramático final de su enemigo y su conversión en mito 
de la ejemplaridad republicana. Mientras que Allende fue entronizado como un mártir de la democracia y un referente de los progresistas del mundo, él hubo de soportar el indeleble estigma de haber sido el máximo responsable de la muerte del prócer y de haber instaurado una dictadura cruel en Chile que causó muchos miles de muertos, detenidos-desaparecidos, torturados, exiliados y represaliados internos. Sobre Allende se propagó una especie de 'leyenda dorada' que el líder fallecido no tuvo la posibilidad de emborronar; mientras que sobre Pinochet se construyó una 'leyenda negra' que el dictador, -tras sus gafas de pasta negra y su gesto siempre adusto- pareció empeñado en confirmar de manera continuada desde el más explícito de los aislamientos como máximo mandatario de la República de Chile. Es cierto que el dictador gozó de un enorme predicamento entre los suyos durante el tiempo que duró su vida política, por lo menos hasta 1998, porque después de la retención londinense se airearon trapos sucios económicos -suyos y de su familia- que perjudicaron seriamente su imagen ${ }^{3}$. Pero no lo es menos el hecho de que Pinochet prácticamente no pudo salir de Chile durante sus años de gobierno (viajó a España, al funeral de Franco, y fue una singularidad significativa), ni que haya pasado a la historia como paladín de la traición a la legalidad republicana chilena y de la crueldad represiva de su régimen.

La llamada 'leyenda dorada' que entronizó al fallecido presidente Allende se extendió

\footnotetext{
El escándalo se destapó en 2005 y dio paso a una minuciosa investigación sobre las cuentas secretas de Pinochet para tratar de esclarecer si parte de ellas podían venir de comisiones por la compra de armas. En octubre de 2007, cuando todavía no se había cumplido un año de la muerte del dictador, se ordenó el arresto y procesamiento de su familia.
}

con rapidez y fortuna y, excepto en algunos detalles, pervivió en el tiempo. Tras el Golpe, todas las informaciones que provienen de la Junta Militar son entendidas como mentiras y propaganda. Paralelamente, los derrotados intentan defender - desde el interior y desde el exterior de Chile- la gestión del gobierno de la Unidad Popular, al mismo tiempo que denuncian la represión de los militares en el poder. En este contexto, comienza a edificarse desde el mundo progresista internacional una imagen mitificada de lo acaecido en Chile (Cáceres y Alcázar 1998).

El eje que vertebra esa versión ficticia es muy claro: pese a algunas voces que lo califican de tibio o ingenuo, Allende es exculpado de su responsabilidad política en el colapso de su presidencia. El argumento central se sustenta en las últimas horas del gobierno de la UP - con las dramáticas imágenes de La Moneda ardiendo por los cuatro costados, tras el ataque cobarde y abusivo con cazas de combate- y no en su desarrollo desde el 4 de noviembre de 1970. El tiempo histórico se comprime: más de 1000 días de gobierno se condensan en media jornada de desigual lucha, con lo que la balanza se inclina en favor de Allende y los defensores de La Moneda. Paralelamente, coexiste una segunda clave interpretativa: Allende es entendido como el mejor representante de la democracia chilena, y su muerte, a manos los facciosos, se homologa a la desaparición de una democracia de alto valor institucional en el contexto latinoamericano. Allende nos es presentado como un republicano ejemplar que ha muerto en combate (Martner 1992: 550). Se apunta así otro dato trascendental para los sectores más a la izquierda de la resistencia chilena: la de la muerte guerrillera de Allende se niega tajantemente el suicidio, por lo tanto-, 
que contará con un narrador y fabulador excepcional, Fidel Castro, en un escenario inigualable, la Plaza de la Revolución de La Habana (Timossi 1974) ${ }^{4}$.

Por último, de la 'leyenda dorada' se desprende un tercer componente reduccionista. Al igual que en otras experiencias populistas de corte progresista, Allende pasa a encarnar al conjunto de un pueblo. Él es su portavoz dilecto y su desaparición es la pérdida de su principal y casi exclusivo defensor (Varas y Vergara 1973).

La crónica de los hechos del día del Golpe refuerza esa síntesis reduccionista. Como señalábamos con Gonzalo Cáceres en el artículo citado, mientras Allende actúa en defensa y estricto apego a la legalidad, los golpistas subvierten la legalidad de manera indigna. Mientras Allende es presentado como un líder carismático, depositario de una voluntad soberana expresada en las urnas y que lo obligaba a desenvolverse en medio de estrictos márgenes éticos, los facciosos amen de singularizar la traición y la mentira en sus versiones más degradadas- asumen el papel de enemigos del pueblo.

La tremenda e irresistible personalización del régimen militar convirtió en indiscutibles una serie de antinomias entre ambos personajes. La primera de ellas es la idiosincrasia de cada uno de ellos; uno, un general del ejército con un marcado y tosco perfil militar; el otro, un

El acto tuvo lugar el 28 de septiembre de 1973, y contó con la presencia de la viuda y las hijas de Salvador Allende. Fidel Castro hizo una recreación casi cinematográfica de la supuesta muerte en combate del líder chileno. Esa versión, la de la muerte en combate, muerte guerrillera, fue la versión oficial de la izquierda chilena durante décadas. El discurso de F. Castro en http://www.archivochile.com/S Allende UP/esp homenajes/ SAhomenaj0002.pdf (Consultado en febrero de 2014) personaje político de naturaleza civil e ilustrada. Sobre esta base toman cuerpo sus rasgos más definitorios: la picaresca teñida de cautela de un hombre taimado y poco claro, frente a la valentía de un presidente aparentemente cándido, franco y sin doblez. No solo sus formas de acceder al poder son opuestas -golpe de Estado, frente a elección democrática-, además también lo son las formas de ejercerlo: Pinochet lo hizo de manera dictatorial y sin piedad para con sus enemigos; mientras que Allende intentó desarrollar su ideal revolucionario a través de la democracia según era concebida en aquellos años desde la izquierda política. No en balde sus discursos representan dos polos opuestos de la comunicación: es la brillante oratoria del demócrata frente a la austeridad castrense del dictador; el discurso del tribuno culto e ilustrado, frente a la arenga autoritaria y la limitación verbal del militar.

\section{La memoria, las memorias, el futuro}

Como hemos hecho en otros trabajos, también en éste pretendemos colaborar modestamente - desde la investigación histórica- en la construcción de un futuro mejor para la sociedad chilena; un tiempo en el que las diversas memorias que existen en Chile sobre los traumáticos años de la Unidad Popular y la dictadura militar dejen de resultar contrapuestas y beligerantes. Es por ello que hablamos de 'memoria para el futuro'.

Debemos aclarar que cuando en este texto hablamos de memoria histórica o de memorias históricas, en singular o en plural, el lector debe saber que nos referimos tanto a los posicionamientos personales producto del recuerdo $o$ de las vivencias individuales 
- que llevamos imaginariamente cargados a la espalda, como en una virtual mochila personal e intransferible-, como a los discursos o usos públicos personales o de grupo sobre el pasado reciente de Chile que conviven, no sin dificultades, en los distintos escenarios políticos y sociales de aquel país (Alcázar 2007).

En la medida que entendemos que la 'memoria para el futuro' es una propuesta que puede devenir positiva para aquellas sociedades que quieren desarrollarse contando con ciudadanos comprometidos con la democracia, con la solidaridad social y con los derechos humanos, pensamos que la propuesta es válida para el Chile que rememora las cuatro décadas transcurridas desde aquella mañana del 11 de septiembre de 1973.

Nos preocupa el hecho de que la existencia de discursos discordantes sobre el pasado histórico puedaresultar incompatiblecon un desarrollo más armónico, y que eso perjudique la convivencia de personas que comparten unas fronteras y una bandera. Es por ello que propugnamos la que podríamos llamar 'memoria mínima común de convivencia', aquella que se sustenta en una serie de consensos básicos sobre el pasado, que es -además- una construcción útil y necesaria para la formación en temas valóricos de la ciudadanía. Nos preocupa y nos motiva la formación de los ciudadanos como tales, con derechos y deberes, y - particularmentela de los estudiantes actuales que serán los ciudadanos efectivos del futuro. Entendemos que es necesario potenciar entre la juventud una buena dosis de conocimiento histórico académico que les permita conciliar su memoria particular de origen familiar con una explicación coherente y fundamentada en la pretensión de objetividad propia de los historiadores.
Y es por ello que pensamos que el período educativo es esencial para la formación de esos futuros ciudadanos adultos ${ }^{5}$. Es importante precisar que entendemos que esta formación no se sustenta exclusivamente en la relación profesor alumno, tampoco exclusivamente dentro del aula, sino que es una formación que tiene que ver con lo que es la vida de las personas y, por tanto, con la conformación de la memoria individual de cada uno de los ciudadanos que sintoniza, entra en contradicción o incluso en conflicto con otras memorias individuales o con las memorias mayoritarias. Así pues, en buena medida hablar de memorias históricas es hablar de lecturas sobre el pasado (Alcázar, 2012).

Esta propuesta de construcción de una 'memoria para el futuro' arranca de la necesidad de generar ciudadanía democrática desde la etapa escolar. Entendiendo que los estudiantes tienen por un lado la información y la formación que reciben en la escuela, la información y la formación que perciben de la familia, y la información y la formación que recogen de su entorno vital más próximo, es evidente que se mueven en un escenario complejo. Si no hay contradicciones significativas entre los diversos niveles de formación e información las cosas van bien en la medida que posibilitan una adscripción de ciudadanía que en las sociedades democráticas ha de sustentarse en los ideales de igualdad, libertad y solidaridad.

Pero esto no siempre ocurre, no siempre hay sintonía con el sistema valórico ideal ya que los discursos explicativos del pasado pueden encerrar grandes contradicciones entre ellos; incluso hasta el punto de ser obstáculos,

Nos referimos fundamentalmente a los estudiantes de enseñanza secundaria. 
a veces insalvables para una convivencia armoniosa y, por lo tanto, para una buena adscripción democrática. Sociedades que han vivido experiencias traumáticas más o menos recientes, como los países de la Europa del sur o los de la América Latina, se encuentran entre las que podemos denominar sociedades en situación postraumática.

\section{Memorias en conflicto en el Cono Sur}

Dejando de lado los casos europeos, entre ellos el español, que todavía evidencia la existencia de memorias contradictorias sobre la guerra civil (1936-1939), la dictadura franquista (1939-1973/75) y la transición democrática (1973/75-1982), hemos trabajado el escenario de los países del Cono Sur que vivieron las dos dictaduras que todavía hoy generan mayor contradicción en cuanto a los relatos existentes (Alcázar y Cáceres 2007). En la Argentina posterior a 1983, Luis Alberto Romero había tipificado cuatro memorias en conflicto (Romero 2006). En 1998, Steve J. Stern detectó, para el caso chileno, otras cuatro de lo que él denomina memorias emblemáticas (Stern 1998). Manuel Antonio Garretón, por su parte, conecta las distintas memorias existentes en su país a lo que llama los hitos fundantes de la memoria nacional chilena (Garretón 2003) e identifica tres: la Unidad Popular y la crisis de un proyecto nacional, el golpe militar y la dictadura y, en tercer lugar, el Plebiscito y la redemocratización política.

Sin que ahora debamos de profundizar más en este terreno, a los efectos de nuestro objetivo con estas páginas, nos parece clarificadora la clasificación de Luis Alberto Romero, quien estableció la existencia de cuatro memorias de la última dictadura argentina que pueden tener - con las debidas matizaciones - valor genérico para el área latinoamericana: la llamada memoria oficial -fundada, dice, por el Informe Nunca Más e institucionalizada por la Teoría de los dos demonios - (Ranalletti, 1999), la militante, la rencorosa y la reivindicativa de los hechos de la dictadura. Una de las características comunes $-y$ ésta es una realidad de extrema importancia - es que para ninguna de ellas la verdad, en el sentido convencional del término, es un objetivo importante. $Y$ es que, como dice Luis Alberto Romero:

\footnotetext{
"Cada uno se acuerda de lo que quiere y se olvida de lo que le da la gana. La memoria es valorativa y categórica, y tiende a considerar las cosas en términos de blancos y negros (...) todo lo que en la memoria es exaltado y contrastado, en el campo del saber de los historiadores es opaco y matizado" (Romero 2006).
}

Así pues, los problemas de las contradicciones entre las memorias del pasado -las de matriz más estrictamente política y partidaria- pueden verse agravadas por el abismo social que separa a esos grupos que están en la parte de arriba y en la de abajo de la pirámide social. Hay, pues, una tensa relación entre la historia reciente y el presente político y social. En los casos chileno y argentino la aparición de las 'memorias militantes' fue, quizá, el único espacio de actuación posible. En buena medida, pensamos, se produjo una contaminación, si se puede hablar así, de la 'memoria de la dictadura' por la desilusión de la democracia. La baja calidad de la democracia recuperada frustró demasiadas expectativas, especialmente las de aquellos que se reconocían como víctimas directas de la dictadura militar, pero también de otros que habían imaginado (no sin razón, dada la simplificación extrema de los discursos partidarios que alentaron grandes expectativas) 
que la democracia iba a mejorar su calidad de vida de forma casi automática. El caso argentino es muy ilustrativo: de las grandes ilusiones de 1983 al "que se vayan todos" de 2001 , se produce un descenso al descrédito del sistema democrático. Peldaños como las asonadas militares de Aldo Rico y otros, la hiperinflación, la amnistía para la Junta Militar, el fin de la convertibilidad, condujeron, en palabras de Luis Alberto Romero, "al punto más bajo del imaginario democrático" (Romero 2006: 3).

En ciertos sectores surge con fuerza una 'memoria militante', que propicia la politización partidista del pasado reciente como herramienta o arma antisistema (democrático). Se trata, con frecuencia, de aquellos que siguen pensando, décadas después, que la democracia -peyorativamente adjetivada como burguesano es sino un disfraz de la clase dominante, que ahora dice repudiar la dictadura de la que se sirvió poco tiempo atrás.

Hay que ser conscientes, sin embargo, que en la otra orilla política también surge una memoria reivindicada por los partidarios del olvido, si se nos permite el juego de palabras. En el caso chileno, muy extremo eso sí, los hay que consideran que no hay nada que reprochar al régimen militar, ni por supuesto al general Pinochet. Estos nostálgicos incluso consideran que al general habría que agradecerle a perpetuidad el haber evitado una guerra civil y haber modernizado Chile. Desde esa posición ofrecen, metafóricamente, una especie de propuesta de tablas en una imaginaria partida de ajedrez:

“(...) los partidarios del olvido (los correligionarios o amigos de los verdugos) vendrían a decir a los partidarios de la memoria (los correligionarios o amigos de las víctimas), poco más o menos: vale más que dejéis de hablar del pasado y que miréis hacia el futuro, porque si hablamos del pasado todos podremos y deberemos hablar" (Alcázar y Cáceres 2007: 421-422).

Se trata de la llamada por Steve Stern 'memoria de la caja cerrada'; esto es: no hablemos del pasado, que es peligroso. Nuestra propuesta va, justamente, en el sentido inverso: hablemos del pasado, pero hagámoslo pensando en el futuro. Aquellos estudiantes que estamos formando como ciudadanos, aquellos con quienes queremos colaborar en la generación de esa 'memoria para el futuro', no son responsables de lo ocurrido antes de que ellos intervinieran en la realidad política y social de sus países, pero deben tomar conciencia de ella. Es en este sentido que recuperamos las declaraciones del ex canciller alemán Gerhard Schröeder pronunciadas en 2005 en Berlín, en el transcurso un acto celebrado con motivo del 60 aniversario de la liberación del campo de exterminio de Auschwitz. Tras afirmar que los actuales ciudadanos alemanes "no tienen ninguna culpa del Holocausto", añadió que "Es un deber común de todos los demócratas enfrentarse al acoso repulsivo de los neonazis y al intento de quitar importancia a los crímenes nazis" (Comas 2005).

Aquello que defendía Schröeder es que la juventud alemana no es responsable del Holocausto, pero debe saber que existió; la española no es responsable de la guerra civil ni de la dictadura de Franco, pero debe conocerlas; igual que tampoco lo es la chilena de la dictadura de Pinochet. No obstante, deben saber que existieron y que, además de inaceptablemente injustas, pueden tener efectos perniciosos para la convivencia si ellos no son agentes activos para revertir la situación.

Como decíamos al principio de estas páginas, los años van cayendo del calendario y los dos 
actores políticos más importantes del Chile reciente siguen representando no solo dos formas de entender cómo ha de organizarse una sociedad compleja, sino que proponen dos maneras de enfrentar la vida, dos formas de ser en relación con los otros, dos pautas de sociabilidad más que contrarias, antagónicas. El civil, seductor, vitalista, ilustrado y tribuno comprometido con la emancipación de los desheredados, contra el militar, dogmático, jerárquico, tosco pero efectivo en la salvaguarda de los valores más conservadores de una sociedad muy clasista.

Observado por el extranjero, Chile presenta en ocasiones una imagen de isla solitaria, ajena a lo que pasa en otras latitudes, ya sean próximas - lejanas. La pervivencia de la confrontación entre Allende y Pinochet es un litigio que solo se entiende desde Chile, de la misma manera que solo dentro de España pudo entenderse la vigencia de un cierto franquismo sociopolítico muerto el dictador. No hay reivindicación alguna del franquismo hoy día, por más que sus herederos políticos sean -unos más que otros- los actuales gobernantes. Franco es hoy un recuerdo incómodo, casi de mal gusto, y a lo más que pueden llegar quienes orbitan en la nostalgia es a negarse en redondo a cualquier condena de lo que fueron las más de tres décadas de dictadura que nos infligió. Los adolescentes españoles de hoy a duras penas pueden decir dos frases sobre aquel general bajito, de voz meliflua y de crueldad probada. $Y$ eso pasará con Pinochet en Chile, con el andar de los años.

No obstante, no debemos ni limitarnos a esperar que el tiempo resuelva nuestros problemas ni auto engañarnos: estas controversias, todavía efervescentes en el país andino, son de consumo exclusivamente interno. Fuera de los límites nacionales, Pinochet está condenado como responsable de una dictadura que violó los derechos humanos de forma cuantitativa y cualitativamente dantesca. Es cierto que los seguidores del general siempre insisten en que el número de víctimas fue muy bajo, como si se tratara del balance de un desastre natural y tres mil víctimas directas con resultado de muerte o desaparición fueran una cifra razonablemente asumible. Claro que eso lo conectan a que se evitó una guerra civil que, suponen, hubiera tenido un mayor coste en vidas humanas. $Y$ ese es un razonamiento, insistimos, exclusivamente de consumo interno.

En cuanto a Salvador Allende, sin embargo, -a diferencia de lo que ocurre con Augusto Pinochet-, hay mayor sintonía entre su imagen de dentro y su imagen de fuera de Chile. Entendemos que sigue encarnando todo un ramo de virtudes entre las que figura la coherencia, la abnegación y hasta la asunción del martirio en defensa de sus principios. Podrá aducirse que es una asignación sesgada, incompleta y que no recuerda los errores que se le pueden atribuir al líder socialista en la dirección de un proceso que tuvo, quizá, más de voluntarismo político que de resultado del análisis concreto de la realidad concreta del Chile -y de la América Latina- de los primeros años setenta del siglo XX. Podrá argumentarse en esta línea de manera muy razonable, pero eso no cambiará esa visión mayoritariamente positiva del hombre que fue capaz de inmolarse en el Palacio de la Moneda una mañana de septiembre del año setenta y tres.

Creemos que la confrontación de los dos actores ha de ser superada y que ha de avanzarse en la construcción de bases más sólidas tanto de la 
concepción de la Historia de Chile como en lo que se denomina la 'política de la Historia'.

A nuestro juicio, esa falta de consensos fundamentales no es estrictamente un problema chileno actual, sino que viene de más atrás de la victoria de la Unidad Popular, aunque la situación se envenena definitivamente a partir de 1970. Y son esas visiones envenenadas las que fundamentan las distintas memorias que encontramos todavía en conflicto.

A finales del siglo pasado, Steve J. Stern (1998) había detectado cuatro de las que él denomina memorias emblemáticas. La primera es la 'memoria como salvación'. Desde esta posición el trauma chileno se ubica antes del golpe militar, un período en el que la economía era arbitraria y catastrófica y la violencia había alcanzado niveles preocupantes. Para quienes se adscriben a esta línea de memoria el odio impregnaba el aire, y el país se dirigía indiscutiblemente hacia una guerra civil que había de ser muy cruenta. Una segunda memoria emblemática es la que Stern denomina 'memoria como ruptura lacerante no resuelta'. El eje sobre el que pivota esta concepción es que el régimen de Pinochet llevó a Chile a un infierno de muerte, tortura y dolor físico y psicológico.

En tercer lugar identifica la que llama 'memoria como una prueba de la consecuencia ética y democrática'. Es una memoria que ponea prueba la consecuencia en la defensa de los valores éticos de las personas, que se ven confrontadas a la realidad dramática de las grandes violaciones de los derechos humanos. Finalmente, la cuarta de las memorias emblemáticas es la de la caja cerrada. El eje vertebrador de ésta es que el Golpe y las violaciones de los derechos humanos subsiguientes constituyen un tema importante pero peligroso y hasta explosivo si se abra la caja y se ventila su contenido. Como el problema no tiene solución y es tan peligroso y complicado, lo mejor es mantener cerrada la caja.

El general Pinochet, en su discurso del 13 de septiembre de 1995, era contundente en esta línea:

"Es mejor quedarse callado y olvidar. Es lo único que debemos hacer. Tenemos que olvidar. $Y$ esto no va a ocurrir abriendo casos, mandando a la gente a la cárcel. OL-VI-DAR, esta es la palabra, y para que esto ocurra, los dos lados tienen que olvidar y seguir trabajando"6.

Nosotros discrepamos frontalmente del general. Mantener viva, por generaciones, la memoria de la caja cerrada es no solo injusto con las víctimas de la dictadura; no solo inaceptable desde la construcción del discurso histórico, es además un grave error político, un error que lastra la convivencia de los chilenos. Resulta, por tanto, imprescindible, avanzar en la [re]construcción del relato sobre el pasado reciente del país.

\section{Romper clichés, acabar con las mitificaciones y enseñar historia a los jóvenes}

La sociedad chilena -en nuestra opinióntodavía no ha sido capaz de ubicar en un lugar apropiado ni al presidente Allende ni al dictador Pinochet, ambos venerados por los suyos y odiados por sus detractores. Los partidarios del primero -del presidente legítimo- tienden a envolverlo entre algodones y a demonizar al general. Por otro lado, los fieles al dictador todavía le otorgan el galardón de gran héroe que

http://www.derechoschile.com/espanol/acerca.htm (Consulta en febrero de 2014) 
salvó al país del comunismo y de la inminencia de una guerra civil, supuestamente buscada por el camaleónico Allende.

Cuando las heridas no están cicatrizadas, pese a las casi cuatro décadas pasadas desde el golpe, es fácil que la tensión se reavive con cualquier pretexto. Esto es -según entendemos desde la distancia- lo que ha ocurrido recientemente en Chile, donde prácticamente - como referíamos al principio - han coincidido en el tiempo una polémica entrevista al ex presidente Aylwin con la celebración de un homenaje a Pinochet, que iba acompañado de la presentación de un documental hagiográfico sobre el general ${ }^{7}$.

Las reacciones a las declaraciones de Aylwin no se hicieron esperar. Isabel Allende, hija del presidente, emitió un comunicado en el que se decía:

\footnotetext{
"El golpe de Estado fue responsabilidad de quienes lo ejecutaron y de quienes conspiraron para derribar al Gobierno constitucional... culparlo o a él o a la UP (la coalición que lo sustentaba) contradice toda evidencia histórica". También el que fuera presidente, Ricardo Lagos, salió en su defensa alegando que el presidente "fue un demócrata. Al momento del golpe de Estado había un Parlamento que funcionaba, había tribunales que funcionaban. Y por lo tanto nada justifica el golpe" (Núñez 2012).
}

Porotrolado, el homenajeaPinochet-autorizado por el Gobierno de Sebastián Piñera- hizo que los disturbios volvieran a las calles de Santiago y se saldaran con 20 heridos y 64 detenidos. La onda expansiva ha llegado también al terreno de la política partidaria; el Gobierno de Piñera -a través de Andrés Chadwick, su portavoz-

Documental dirigido por Ignacio Zegers (http://www.youtube. com/watch?v=8kGWGTa0y_M) (Consultado en febrero de2014) que, además, se ha visto en vuelto en otra polémica y es que el cineasta chileno Miguel Littin ha denunciado el robo intelectual de imágenes de su película Compañero, Presidente. adoptó una posición de neutralidad ante el acto al que dicen no haber sido invitados ${ }^{8}$. Pese a la asepsia gubernamental, el presidente Piñera se ha visto salpicado directamente por la cuestión. En una entrevista concedida a la BBC pocos días después del homenaje, el presidente de Chile daba por zanjada de manera brusca el encuentro después que el periodista le preguntara a propósito de la polémica sobre el homenaje a Pinochet (Lissardy 2012).

Más allá de las declaraciones, lo que parece indiscutible es que pasan los años y la confrontación 'Allende vs. Pinochet' sigue abierta, lo que no es sino la evidencia de que continúan existiendo distintas y antagónicas memorias de la historia reciente de Chile.

Desde la responsabilidad que compete al pueblo chileno respecto a su presente y su futuro, parece que sería necesario revisar críticamente los discursos existentes y comenzar a construir un discurso distinto, así como a superar la contraposición de las dos figuras que es un ejercicio con escasos dividendos que no sean negativos. Es necesario aceptar la diferencia de la responsabilidad en el gobierno del país: uno, Allende, tres años; y el otro, Pinochet, diecisiete. $Y$ es imprescindible asumir que mientras que el primero consideró un servidor leal al segundo hasta la misma mañana del golpe, Pinochet consideró siempre enemigos a Allende y a todos sus partidarios. Es necesario aceptar que el golpe militar se puede entender, pero en ningún caso justificar; de la misma manera que si se comprende que el golpe fue bien recibido

"El Gobierno de Chile no es partidario del homenaje a Pinochet", Europapress.es, 06.06.2012. http://www.europapress.es/latam/ chile/noticia-chile-gobierno-no-partidario-homenaje-pinochetdefiende-derecho-organizacion-celebrarlo-20120606052157.html (Consultado en febrerode2014). 
por mucha gente como la única salida al caos, no por ello se acepta su desarrollo posterior, particularmente las violaciones masivas, sistemáticas y continuadas de los derechos humanos más elementales.

Resulta necesario superar los mitos que existen de un lado y desde el otro y trascender a efectos de la comprensión del pasado la visión estrictamente ética. Si nos enfrentamos desde la ética a los dos periodos o a los dos personajes no hay discusión: hay un gobierno legítimo, convulso e inoperante en su última fase si se quiere, pero legítimo; y hay un gobierno ilegitimo y violador de los derechos humanos que usurpó el poder al primero por la fuerza de las armas. Esto no puede ponerse en discusión, ni se puede justificar con los viejos y manidos clichés de la guerra civil inminente, ni de los miles de hombres armados dispuestos a dar un baño de sangre a Chile, puesto que conocemos suficientemente bien los hechos históricos probados que desmienten estas afirmaciones.

Aceptar los errores, las insuficiencias, los déficits y las contradicciones del periodo de la Unidad Popular o del proyecto gubernamental de Allende no puede ponerse en el mismo plano de simetría respecto al desempeño de una dictadura militar -dictadura, no régimen militar, dictadura ${ }^{9}$ - larga, cruel y cruenta. Por tanto, se trata de abandonar las mitificaciones y de superar las imágenes estereotipadas a

El Consejo Nacional de Educación (CNED) de Chile, en su sesión del 9 de diciembre de 2011, erradicó el concepto de "dictadura militar" de los ejes temáticos de Historia para sexto básico (enseñanza secundaria). Eso dio lugar a una importante respuesta ciudadana en forma de una carta abierta a Harald Bayer, Ministro de Educación del Gobierno de Sebastián Piñera, que recogió miles de firmas. https://sites.google.com/site/dictaduraporsunombre/ (Consultado en febrero de 2014). propósito de los representantes de dos visiones antagónicas de la historia reciente de Chile. Es necesario romper con la idea de que el derecho de propiedad es equiparable al derecho a la vida, como es necesario situar a ambos personajes en un contexto de Guerra Fría, de confrontación Este-Oeste, de blancos y de negros, o de rojos contra azules, en el que la defensa de los valores propios -revolucionarios o conservadorespodía llegar a estar por encima de cualquier otra consideración política.

Pensando fundamentalmente en las generaciones que no vivieron ni los años de la UP ni los de la dictadura militar, sería deseable construir un relato explicativo del pasado reciente desde la pretensión de objetividad que es propia del oficio de historiador, que permita superar los planteamientos esencialistas y que reconozca las diferencias políticas e ideológicas internas, incluso las diferencias de proyectos sociales, desde la convicción que pueden ser perfectamente compatibles en la construcción y el desarrollo de una convivencia colectiva razonablemente armónica (Villares 2002: 27).

En este sentido, ante la confrontación de los partidarios de dos actores políticos de las dimensiones de Salvador Allende y de Augusto Pinochet, es necesario aceptar que estamos ante dos proyectos políticos diametralmente opuestos en cuanto a sus principios y a sus sistemas de valores. Uno se alinea con las corrientes favorables a la reducción de las distancias entre los distintos grupos o clases sociales, haciendo énfasis en el papel regulador y redistributivo del Estado, que ha de garantizar que los intereses privados estén subordinados a los públicos, especialmente para mejorar las condiciones de vida y trabajo de los sectores más humildes; y eso mientras promueve un 
sistema de organización de la sociedad que considera más justo y que identifica con el socialismo de inspiración marxista.

Mientras tanto, el otro construye su programa político sobre la autoridad militarizada e indiscutible, el orden social rígidamente jerarquizado y la inviolabilidad de la propiedad privada que no puede estar subordinada al intervencionismo del Estado, todo ello desde la identificación con lo que denomina los valores occidentales y cristianos; valores que considera antagónicos con el materialismo y el ateísmo que adjudica al socialismo. A ambos hay que enmarcarlos en un mundo dividido en dos, en un escenario que llamamos Guerra Fría y que no admitía ni las medias tintas ni los matices políticos.

Por otro lado, las pautas de gobierno de uno y de otro se sustentan sobre presupuestos completamente diferentes. Las de Salvador Allende, de manera no exenta de importantes contradicciones, se cimentan en el mantenimiento de la legalidad republicana, aunque con un discurso equívoco que en la medida que identifica la meta final con la Cuba castrista, -pese a que enfatiza que la ruta será bien distinta a la de los guerrilleros de la Sierra Maestra-, era una propuesta abierta a diversas interpretaciones, muy probablemente porque quería dar satisfacción a la pluralidad de sensibilidades y de grupos ideológicos que coexistían dentro de la UP y en su inmediata periferia. Adolecía el proyecto, además, de una concepción homologable a lo que hoy día entendemos por un funcionamiento democrático, en la medida que era deudor de una concepción instrumentalista de la democracia que la izquierda política mundial, muy especialmente la que se reclamaba de filiación marxista en su sentido más estricto, tenía absolutamente arraigada. La democracia aparecía -para quienes creyeron en la 'Vía chilena', dentro y fuera del país- como un sistema mediante el cual esa misma izquierda podía acceder al poder de manera no violenta, pero en la medida que se consideraba que 'el pueblo' ya había alcanzado su estación término, el mantenimiento de las formas de la llamada 'democracia burguesa' era algo absolutamente prescindible.

Los presupuestos constitutivos del gobierno de Pinochet, por su parte, son los que sustentan las Ilamadas 'dictaduras de seguridad nacional' de los años sesenta, los setenta y los ochenta, en sintonía por tanto con las directrices de protección hemisférica frente al expansionismo soviético que tanto se temía desde Washington, especialmente, después que la pequeña Cuba se convirtiera en una especie de portaviones de la supuesta pandemia revolucionaria de filiación moscovita.

En su desarrollo, el Gobierno militar de Pinochet practicó con fruición la persecución hasta el exterminio del enemigo interior al que, desde el principio, despojó no solo de su nacionalidad sino, en la práctica, de su condición de ser humano; y lo convirtió en sujeto receptor de todas las violaciones de la doctrina de los derechos humanos básicos. Si el gobierno al que Ilamaba 'comunista' había puesto en cuestión el sacrosanto derecho de propiedad había sido porque no se habían preservado adecuadamente los sistemas de control social, y porque se había permitido la proliferación de las organizaciones que ponían en cuestión el sistema sociopolítico existente, proponiendo su transformación radical y revolucionaria. Solo desde una acción resuelta y radical - quirúrgica, 
como gustaban decir; de amputación hablará Pinochet a Miguel de la Cuadra Salcedo en una entrevista para TVE realizada en septiembre de $1973^{10}$ - podía ponerse freno a ese desbarajuste político y revertir la situación.

Allende en sus discursos siempre afirmaba estar convencido de que solo la democracia era la llave para llegar al socialismo, por lo que apostó - con modestia, le dijo a Regis Debray en la conversación que ambos mantuvieron en $1971^{11}$ - por lo que él creía una forma novedosa de transitar hacia el socialismo en los tiempos del mundo bipolar. Tan cargada de ilusiones como preñada de contradicciones, la llamada 'Vía chilena' se nos antoja hoy día como un producto muy singular de su tiempo; una propuesta frágil que se sustentaba en un concepto de democracia bien distinto del de nuestros días, en la medida que -como hemos dicho- se apoyaba en una instrumentalización que hoy nos resulta inaceptable. La defensa de la democracia -de la democracia sin apellidosaparecería para la izquierda política mundial de la mano del Partido Comunista Italiano (Gramsci, Togliatti, Berlinguer 1978); precisamente, tras la caída del gobierno de la UP y como resultado de las reflexiones que su fracaso y su derrota suscitó (Riquelme 2007). La visión de Allende, mucho más abierta no obstante que la de una buena parte de quienes conformaban la propia coalición del Gobierno que él presidía, se legitimaba a si misma tras una razón fundamentalmente ética que se compadecía mal con las correlaciones de fuerzas políticas realmente existentes no solo en Chile, sino en América Latina en su conjunto.

En ese escenario de Guerra Fría, en un hemisferio en el que la potencia hegemónica eran los Estados Unidos de América, el precio a pagar por aquellos que habían osado desafiar el status quo anterior no solo a 1970, sino al de los años posteriores a la victoria castrista, había de ser alto. El régimen militar, por tanto, se empleó a fondo, en sintonía con otros regímenes continentales de la misma matriz y se decidió a extirpar lo que denominaban el 'cáncer marxista'. Si el comunismo no era una ideología, sino que era una enfermedad -como había dicho J. Edgar Hoover, director del FBI durante casi medio siglo-, el general Pinochet como otros de sus coetáneos, civiles y militares, estaba decidido a curar a Chile de ese mal.

Sería bueno, pues, ubicar a ambos personajes en su época y en su contexto, y asumir mediante el conocimiento y la enseñanza de la Historia- un pasado que podemos disfrazar pero no cambiar. Y sería bueno ofrecer un discurso coherente y veraz a las jóvenes generaciones que no debieran ser rehenes de un pasado reciente -pero cada vez más alejado- sobre el que no tienen responsabilidad alguna. 2014) com/47478157 (Consultado en septiembre de 2016). 


\section{Bibliografía}

Alcázar, J. 2007. "Continuar viviendo juntos después del horror. Memoria e historia en las sociedades postdictatoriales", en Ansaldi, W. (dir.): La democracia en América Latina, un barco a la deriva. Buenos Aires: F. C. E.

Alcázar, J. y Cáceres, G. 2007. "Clío contra las cuerdas: memorias contra historia en el Chile Actual". Memorias históricas de España (siglo XX). Josefina Cuesta (Dir.). Madrid: Fundación Francisco Largo Caballero. pp. 412-427.

Alcázar, J. 2009. "A modo de conclusión. La segunda muerte de Augusto Pinochet", en [Alcázar, J. 2009]: Yo pisaré las calles nuevamente. Chile, revolución, dictadura, democracia (19702006). Santiago: Editorial Universidad Bolivariana.

Alcázar, J. 2012. "Historia desde el cine [y con la literatura] para la educación". Revista Brasilera de Estudios Pedagógicos. Vol. 93. $\mathrm{N}^{\circ} 235$, set/dez. pp. 645-666.

Alcázar, J. y Pinazo, S. 2013. "La memoria para el futuro, tres propuestas educativas para el desarrollo social sostenido" (en prensa).

Cáceres, G. y Alcázar, J. 1998. "Allende i la UP: cap a una deconstrucció dels mites polítics xilens", en El Contemporani, $\mathrm{N}^{\circ}$ 15. Barcelona: Afers/Centre d'Estudis Històrics Internacionals de la Universitat de Barcelona. pp. 33-41

Comas, J. (2005): "Schröder: "No tenemos culpa, sí responsabilidad". El País, 26.01.2005

Garretón, M.A. 2003. "Memoria y proyecto de país". Revista de ciencia política.Vol. XXIII. № 2. Santiago de Chile. pp. 215230.

Gramsci, A., Togliatti, P., Berlinguer, E. 1978. El compromiso histórico. Barcelona: Crítica.

Lissardy, G. 2012. "La pregunta sobre Pinochet que BBC Mundo no le pudo hacer a Piñera", Gerardo Lissardy, en BBC
Mundo. Una voz independiente, http://www.bbc.co.uk/mundo/ noticias/2012/06/120622_entrevista_pinera_chile_pea.shtml (Consultado en junio 2016).

Montes, R. 2012: "Entrevista a Patricio Aylwin. El presidente se confiesa" El País. Madrid. (Consultado el 27 de mayo de 2012)

Núñez, R. 2012. "Chile: Allende y Pinochet, dos fantasmas que se niegan a desaparecer". Núñez, R., en Infolatam,

Ranalletti, M. 1999. "La construcción del relato de la historia argentina en el cine, 1983-1989”. Film-historia. Volumen IX. № 1. Barcelona.

Romero, L. A. 2006. "El pasado que duele y los dilemas del historiador ciudadano", en http://www.unsam.edu.ar/ escuelas/politica/centro_historia_politica/romero/Criterio.pdf. (Consultado junio 2016).

Riquelme, A. 2007. "Los modelos revolucionarios y el naufragio de la vía chilena al socialismo". Dossier édité par Eugénia Palieraki et Marianne González L'idée de Révolution en Amérique latine du 19e au 20e siècle. Paris : Nuevo Mundo Mundos Nuevos.

Stern, S. 1998. "De la memoria suelta a la memoria emblemática: hacia el recordar y el olvidar como proceso histórico (Chile, 1973-1998). Las conmemoraciones: las disputas en las fechas 'in-felices'. Jelin, E. (Comp.). Madrid: Siglo XXI.

Timossi, J. 1974. Grandes alamedas. El combate del presidente Allende. La Habana: Editorial de Ciencias Sociales.

Varas, F., y Vergara J. M.1973. Operación Chile. Barcelona: Pomaire.

Villares, R. 2002. "El debate sobre la historia de España o la política de la historia". Història d'Espanya: què ensenyar. Debat al voltant de la historia d'Espanya. Alcázar, J. (Coord.): València: PUV. 
